\title{
Tailored Financial Incentives to Fight Medical Non-Persistence in Therapeutic Treatment: A Behavioral Economic Engineering Approach
}

\author{
Behnud Mir Djawadi, PhD\& \\ University of Paderborn
}

\author{
René Fahr, PhDa \\ University of Paderborn, IZA
}

Florian Turk, $\mathrm{PhD}$

GlaxoSmithKline plc

January 2016

\begin{abstract}
The development and design of financial incentive schemes as a sustainable and cost-effective intervention strategy to foster effectiveness of medical interventions remains a significant challenge in health care delivery.

Based on the findings of the conceptual model of medical non-persistence we test three different financial incentive schemes. These incentives are derived upon concepts of behavioral economics, in particular mental accounting, prospect theory and choice bracketing, and incorporated into deposit, copayment and bonus schemes. We conduct randomized laboratory experiments to evaluate the performance and effectiveness of each incentive scheme on persistence behavior under controlled conditions. Participants in the experiment are students remunerated according to their performance in the experiment.
\end{abstract}

\begin{abstract}
We find that financial incentive schemes based on the principles of prospect theory significantly improve treatment persistence compared to the situation where there are no incentives at all. This finding implies that the simple but smart reallocation of co-payments and co-payment support between the treatment initiation phase and treatment maintenance phase represents an effective way of promoting persistence behavior.

This study delivers first applications of behavioral interventions based on theoretical foundation. Using the method of experimental economics the study serves as a first proof of concept of a scalable way to design, calibrate and test the effectiveness of financial incentives on behavioral change. This approach is inevitable for broad application in real world as it minimizes the need for patient research while clarifying the impact of interventions under controlled conditions before these interventions get implemented in the field.
\end{abstract}

Keywords: Financial incentives, Medication persistence, Medication compliance, Behavioral economics, Laboratory experiment, Behavioral Economic Engineering

JEL classification: C91, I11

\footnotetext{
* Department of Management, University of Paderborn, Warburger Str. 100, D-33098 Paderborn, Germany. Email: behnud.mir.djawadi@upb.de, phone: +49-(0)5251-60-2093, fax: +49-(0)5251-60-3550

- Corresponding author. Chair for Corporate Governance, Department of Management, University of Paderborn, Warburger Str. 100, D-33098 Paderborn, Germany. Email: rene.fahr@ upb.de, phone: +49-(0)5251-60-2090, fax: +49-(0)5251-60-3550.

- Head Global Market Access \& Healthcare Solutions, GlaxoSmithKline plc, GSK-House, 980 Great West Road, UK-TW8 9GS Brentford, Middlesex, UK. Email: florian.x.turk@ gsk.com, phone: +44-(0)7887-055376.
} 


\section{Introduction}

1 With flattening and partially shrinking healthcare budgets and the aim to increase coverage,

2 quality and services, improving health care delivery efficiency and effectiveness is central in

3 health care decision making. Providers of care as well as health care services and products are

4 increasingly being held accountable for delivering health outcomes (effectiveness). But the

5 health care delivery value chain is complex. It includes suppliers like pharmaceutical

6 manufacturers, providers like hospitals and physicians as well as patients as "prosumers" (co-

7 producers). Thus the efficiency and effectiveness of health care delivery is highly dependent on

8 patient's behavior. Not surprisingly the next major cycle of improvements in health outcomes

9 is seen as not only being driven by new clinical science, but by behavioral change. More and

10 more emphasis is on gathering evidence to identify the interventions that are most effective at

11 improving health outcomes, and then realigning the behaviors of all stakeholders - patients,

12 providers, manufacturers and others - around these interventions.

13 One of the suboptimal behavioral patterns of striking magnitude and thus barrier to efficiency

14 of health care delivery and achievements of desired levels of health outcomes is poor medical persistence to long-term therapy. (World Health Organization (WHO), 2013). The term medical

16 persistence is defined as "the duration of time from initiation to discontinuation of therapy" and documented in a manuscript by the Issues and Methods Definitions Working Group of the International Society of Pharmacoeconomics \& Outcomes Research (ISPOR) (see for details: (Cramer et al., 2008)). Assuming that the medicine and the doses have been prescribed appropriately, the prevalence of mostly intentional non-persistence behavior, especially for 21 chronic diseases such as cholesterol, diabetes, hypertension, HIV, obesity, smoking or tuberculosis, is a serious concern as it undermines the effectiveness of medical treatments and leads to significant clinical and economic consequences (Donovan and Blake, 1992; Hughes et 
1 shifting more financial risk to suppliers, they will need to effectively and efficiently change

2 patient behaviors to manage this risk.

3 Boosting persistence will require significant shifts in patient behavior. But patient behaviors

4 have so far been resistant to change. A variety of interventions to improve patient persistence 5 evaluated to date, ranging from simple adjustments in the medication regimen to complex 6 multidisciplinary interventions, produced only small to moderate effects on patient behaviors 7 (Djawadi and Fahr, R., Turk, R., 2014; Kripalani et al., 2007; McDonald et al., 2002). 8 Therefore, changing incentives are playing a central role in changing behaviors. The present 9 paper deals with financial incentives as an intervention strategy to keep patients on the path of 10 their medical treatment. The effectiveness of financial incentives has been theoretically 11 substantiated and empirically supported in different economic settings, most prominently in the 12 labor market (Lazear, 2000; Prendergast, 1999). However, health care research still lacks engineered mechanisms with financial incentives tailored to patient behavior. The major 14 critique hereby lies in the lack of methodological rigor which leaves many questions about the effectiveness of financial incentives unanswered. With only few exceptions (Volpp et al., 2008b; Volpp et al., 2008a), most clinical studies do not report why a certain type and magnitude of incentive was used. Given the variety and heterogeneity of the reviewed studies in terms of compliance and persistence definition, type of disease, size of sample population, length of treatment, existence of follow-up and persistence outcome measurement, a proper comparison and evaluation of different financial incentive schemes is impossible.

21 In particular, there are two reasons why the appropriate development and design of financial 22 incentive schemes as a sustainable and cost-effective intervention strategy to improve 23 persistence behavior remains a significant challenge for health care research:

24 1) Standard economic cost-benefit models assume a patient who responds to incentives in a 25 rational way. Yet, findings from behavioral economics which integrates the fields of economics 
1 and psychology suggest that patients fail to make behavioral changes and have predictable

2 biases that affect the decision-making with recommended medication usage (Asch et al., 2012;

3 Kullgren et al., 2013; Loewenstein et al., 2007; Long et al., 2012; Volpp et al., 2008b; Volpp

4 et al., 2008a; Volpp et al., 2009b; Volpp et al., 2009a).

5 2) With a focus on clinical trials (randomized and controlled as well as pragmatic) to assess the

6 impact of behavioral incentives there is a lack of a scalable approach to design, test and calibrate

7 tailored incentive schemes. The empirical research based on observational data or clinical trials

8 further lacks the ability to compare the effectiveness of different financial incentive schemes

9 within the same environmental setting (Cleemput et al., 2002; Vermeire et al., 2001).

10 Consequently, financial incentives are rarely cost-effective and are more or less the result of

11 arbitrary guess-work (Volpp et al., 2009b).

The aim of the study is to design 1) financial incentive schemes build on principles of behavioral economics to better describe and address patient decision-making biases in health contexts and to use 2) behavioural laboratory experiments as a scalable way to evaluate the performance of the financial schemes. In particular, the design of our three financial incentive schemes are based on the behavioral concepts of mental accounting (Thaler, 1985, 1999), prospect theory (Kahneman and Tversky, 1979) and choice bracketing (Read et al., 1999). Using the method of experimental economics, each financial incentive scheme is tested in a series of randomized laboratory experiments with student participants allowing for clean causal inferences about the performance of one single incentive scheme on improving persistence. By incorporating the main features of a stylized medical treatment into an experimental setting, our approach follows the procedure of behavioral economic engineering studies in management science (Bolton et al., 2013). Thereby, behavioral economic engineering denotes the science of designing realworld institutions and mechanisms that align financial incentives and patient behavior with the underlying goal of improving persistence (Bolton and Ockenfels, 2012; Roth, 2002). It offers a 
1 method to investigate how patients react to different kinds of financial incentives under

2 controlled conditions prior to the institution's launch on a large social scale. We proceed as

3 follows. In a first step we briefly describe the conceptual framework of medical non-persistence

4 by Djawadi et al. (Djawadi and Fahr, R., Turk, R., 2014) which serves as the theoretical

5 foundation to derive the mechanisms of our financial incentive schemes. In a second step, we

6 illustrate how we designed a randomized economic experiment to test the performance of each

7 financial incentive scheme under controlled conditions and present the behavioral results.

\section{Methods}

\section{Conceptual Framework of medication persistence}

We use the conceptual framework of medical non-persistence by Djawadi et al. (Djawadi and Fahr, R., Turk, R., 2014) to derive and design the mechanisms of our financial incentive schemes. The framework explains medical non-persistence from the perspective of behavioral economics to understand patient's preferences for discontinuing with therapy over time. Referring to the dynamic course of persistence behavior typically observed in medical treatments (Siiskonen et al., 2007; van Wijk, B. L. G. et al., 2005), it is argued that the costbenefit assessment of continuing with therapy on the side of the patient depends on the timing of the treatment. Three time phases are identified. The "phase of invasion" represents the beginning of a medical treatment where the patient takes the medicine without experiencing any improvements because a certain time and a certain threshold level are needed for the medicine to reach plateau efficacy ("on" characteristics of drug). After this threshold level is met, patients are observed to comply extremely well ("phase of high persistence"), yet fail to do so at a specific point in time and then start discontinuing with therapy ("phase of expected variation in persistence behavior"). In order to reflect the three typical persistence phases in medical treatments and to account for possible dynamic inconsistencies in patient preferences over time, the patient's decision-making process is assumed to follow the principles of mental 
1 accounting (Thaler, 1985, 1999). The framing of the outcomes of continuing with therapy in

2 terms of gains and losses follows the prospect theory (Kahneman and Tversky, 1979). The

3 predictions of the conceptual framework were validated using the method of experimental

4 economics. The experiments show that a subject's perceptions about economic gains and losses

5 of continuing with therapy change over the course of a treatment, causing a switch to non-

6 persistence at a particular point in time. Subjects keep choosing the option with lower risk until

7 the experienced losses are compensated. Consistent with the predictions of the conceptual

8 model and opposed to rational choice behavior, once the losses are evened out, subjects value

9 any further economic gains of continuing with therapy to a much smaller extent and

10 consequently reveal preferences for the more risky choice of discontinuing with therapy until

11 the end of the treatment.

12

\section{Engineering and Testing the Performance of Financial Incentive Schemes}

Based on the empirical findings of the conceptual framework of Djawadi et al. (Djawadi and Fahr, R., Turk, R., 2014) and on broad empirical evidence that people suffer from systematic biases in medical decision-making, reacting to incentives differently than proposed by rational choice theory, we include and tailor concepts from behavioral economics into our financial interventions to enable a behavioral change. To empirically evaluate the performance of each financial incentive scheme we proceed as follows: we use the exact experiment of Djawadi et al. (Djawadi and Fahr, R., Turk, R., 2014) which we call for the sake of clarity BASE and modify the choice set of BASE accordingly to investigate how persistence behavior changes if subjects are provided with financial incentives. As we change only the form of incentive scheme while keeping all other factors of BASE constant (e.g. same economic environment, same course of actions, same population sample and the same persistence outcome measures), we can make causal inferences about the relationship between the performance of one single incentive scheme and change in persistence behavior. Another advantage of this approach is 
1 the fact that new institutions like different financial incentive schemes can be tested in the

2 laboratory before they are implemented in the field, avoiding a costly trial-and-error approach

3 as it has happened in various clinical trials and allowing for scalability. Our first financial

4 incentive scheme DEPOSIT corresponds to a deposit contract in which patients incrementally

5 pay a constant amount into a deposit and receive their payments from a specific point in time

6 on, stepwise back (for the use of deposit contracts in weight reduction see (Volpp et al.,

7 2008a)). The incremental payments into the deposit extend the phase in which patients are still

8 in the domain of losses. According to the quasi-hedonic editing rule as part of mental accounting

9 to evaluate economic outcomes in dynamic settings (Thaler and Johnson, 1990), patients will

10 have a strong tendency to compensate all previous losses with the lowest risk possible which

11 can only be achieved by remaining persistent. Hence, we expect risky choices of non-

12 persistence to be postponed to later periods compared to BASE, as now previous losses can only be compensated to the full extent if the individual continues with therapy until almost the end of the time horizon. Our first hypothesis is stated as: to remain longer in the domain of losses, more time periods are needed to compensate the endured losses by limiting risks as much as possible. Thus an increase in persistence is expected compared to BASE.

The second financial incentive scheme COPAYMENT aims to reduce the costs of being persistent by lowering copayments for obtained medicines. This experimental intervention considers the diminishing effect of future gains over time which is predicted by the value function of the conceptual framework. As future gains are valued less when individuals have compensated all their previous losses, lowering the costs associated with being persistent in the domain of gains makes persistence behavior more attractive for subjects. The increase in 
1 subjects compared to BASE will switch to non-persistence. Our second hypothesis is 2 formulated as: H-COPAYMENT: By lowering the costs associated with persistence behavior in time periods where previous losses are compensated, it is expected that subjects value future gains of being persistent in the domain of gains more than in BASE, leading to more persistence behavior compared to BASE.

7 In the third financial incentive scheme BONUS we make bonus payments to patients. Empirical 8 evidence from several medical treatments shows that small rewards on a frequent basis have a 9 greater impact on persistence behavior than a single, large payment sometime along the treatment (Higgins S. T. et al., 2000; Lussier et al., 2006). The psychological concept of choice bracketing as part of mental accounting suggests that individuals divide a sequence of risky choices into smaller decision sets and evaluate them independently one at a time (Read et al., 1999). This mental regrouping and narrowing of repeated decisions serves as a facilitating strategy to reach long-term goals with short-sighted behavior. Paying patients frequently thus creates a mental shift in evaluating persistence behavior only up to the next payment rather than to the end of the treatment. The mechanism of our incentive scheme therefore aims to divide the time horizon into discrete decision blocks and pay the patient a bonus at the end of each block. As patients only have to evaluate the costs and benefits of persistence behavior within each block we expect decisions to be more aligned with rational choice theory. We state the following hypothesis: to evaluate the costs and benefits of persistence behavior only up to the next payment and to make choices more aligned with rational choice theory. Subjects who are persistent in 
the beginning of the time horizon will therefore continue longer with therapy compared to BASE.

3 To clearly measure the effect of the financial incentive schemes on observed persistence

4 behavior, it is crucial to disentangle the 'incentive-effect' from other effects which possibly 5 play a role in the individual's decision-making process. Since the decisions are to be made 6 under risk and uncertainty, the attitude towards risk is a crucial aspect that must be accounted 7 for. According to Frederick (Frederick, 2005), risk preferences are strongly tied to a person's cognitive ability and therefore constitute an important determinant when making risky decisions. The importance increases if, for example, high risks in form of a severe relapse are at stake. The psychological literature further suggests placing risk perception and risk attitudes into a broad psychological context. Additionally, Straub (Straub, 1995) as well as Goeree et al. (Goeree et al., 2003) and Schmidt et al. (Schmidt et al., 2003) provide evidence that risk attitudes and observed decisions in the main experiment are aligned with each other. Based on these considerations, it is assumed that individuals exhibiting more risk-aversion will choose the least risky option and are therefore more persistent. Thus, to clearly disentangle the effect of risk perceptions and persistence behavior, we control for risk attitudes by using a lottery choice framework which was developed by Dohmen et al. (Dohmen et al., 2010) and was found to elicit risk preferences on a valid basis. Our last hypothesis is:

H-RISK: More risk-seeking individuals will tend to switch earlier from continuing with therapy to discontinuing with therapy compared to their more risk-averse counterparts.

Experimental Design

23 We firstly present the experimental design of BASE in detail and then describe which parameters we calibrated to test the performance of each proposed financial incentive scheme. The original experiment is designed as a simple investment game and creates an economic 
1 environment which is equivalent to a medical treatment (see Figure 1). Subjects decide in an

2 investment plan over several decision periods between two investment options: lottery A and

3 lottery B. These lotteries represent the economic consequences of continuing with therapy as a

4 trade-off between benefits and costs, and capture the entailed risk of suffering a non5 compensable medical relapse. To simulate the course of events inherent in medical treatments

6 from an economics perspective, prior to the investment plan the experiment starts with a

7 working stage. The working stage is the economic equivalent of the "phase of invasion" and is 8 intended to incur costs for the subjects. Subjects work in the laboratory by exerting a real effort

9 task which is known in the literature as the slider task (Gill and Prowse, 2012). A screenshot

10 of the slider task is provided in Appendix A. In the slider task, subjects position tiny sliders on 11 the computer screen which requires both effort and time. Subjects get to know how much money 12 the completion of the slider task is worth, but they are only provided with a fraction of this amount. Hence, comparable to patients in medical treatments, subjects in the beginning of the experiment invest effort and endure a loss of foregone benefits, in this case monetary payoffs, when they start the investment plan.

Figure 1: The two stages of the experiment and expected persistence behavior

In each decision period of the investment plan, the subject can choose between lottery A and lottery B respectively. While each lottery has the same payoff structure, they differ in their risk profile of receiving the positive outcome. Lottery A is the more and lottery B is the less risky lottery. In order to play the less risky lottery B subjects have to invest a certain amount of money, i.e. the choice of the less risky option entails costs but increases the chance of receiving the positive outcome. The monetary costs when playing lottery B correspond to costs of persistence behavior in a medical treatment (for example opportunity costs, costs in form of 
1 side effects or complex intake procedures). Lottery A represents non-persistence behavior and

2 comes with no costs. Once the subject makes a choice between the two lotteries a randomization

3 device determines whether the lottery was won or lost according to the probabilities that are

4 associated with each outcome of the chosen lottery. Depending on the choices, the subject has

5 the possibility to compensate his/her losses from the working stage and increase the individual

6 wealth to a substantial positive amount. A crucial feature of the experiment is the "sudden death

7 mechanism". Once the subject loses the lottery the subject cannot take any further decisions in

8 the experiment. It is noteworthy that both lotteries may lead to a drop out, but the probability

9 for a drop out is far larger in lottery A, in particular when choosing lottery A repeatedly. This

10 feature closely corresponds to a medical treatment. If patients partially or completely stop

11 taking their medication as prescribed, they will soon drop below the threshold level of the

12 substance being efficacious ("off" characteristics respectively duration of action of drug). If the

13 threshold level is not reached, the risk for a relapse increases.

\section{Calibration of Experimental Parameters}

We calibrate the relevant parameters in the three experimental treatments with financial incentives (DEPOSIT, COPAYMENT and BONUS) as follows.

The working stage is identical for every single treatment. Subjects have no time limit for working on the slider task and only when all 48 sliders are positioned correctly the task is completed. This task is worth 8 units of the experimental currency Taler, but the subjects have to pay 6 Taler in order to enter the next stage. Thus, each subject starts the investment plan with a loss of 6 Taler.

The investment plan consists of at most 12 periods. In each period, the subjects have to choose between lottery A and B which both yield either 2 Taler or 0 Taler. A screenshot of the choice display is reproduced in Appendix A. In lottery A, the chance of winning 2 Taler occurs with a probability of $70 \%$ and of losing, i.e. getting nothing, with a probability of $30 \%$. In lottery B, 
1 the chance of winning 2 Taler occurs with a probability of $95 \%$ and of losing the lottery with a

2 probability of $5 \%$. However, in order to be able to play the less risky lottery $\mathrm{B}$, the subject has

3 to invest 1 Taler. In the case of winning the selected lottery, the subject is able to choose

4 between the two lotteries once again in the following period. The monetary earnings of the

5 chosen lotteries are accumulated over the periods. When a subject loses the lottery, he is not

6 able to make any further decisions. The current account balance remains unchanged until the

7 end of the experiment. The outcomes and the corresponding probabilities of the two lotteries

8 are chosen in a way that the strategy for maximizing expected value in all experimental

9 intervention treatments is to choose lottery B in the periods 1 until 11 and then switch to lottery

10 A for the last period 12. The detailed calculation can be found in Appendix B. Hence, in analogy

11 of a medical treatment, subjects have a higher probability of maintaining their current health

12 status without suffering a relapse if they comply. In our framework this means constantly

13 choosing lottery B throughout the decision sequence.

14 The three financial incentive schemes differ with respect to the timing at which subjects

15 compensate their losses over the course of the experiment. In DEPOSIT, for each decision in

16 the periods 1 to 6 , subjects are required to pay an additional amount of 0.5 Taler which is paid

17 back to them step by step in the subsequent periods 7 to 12 . Thus, subjects can compensate their previous losses from the "phase of invasion" in period 9 at the latest. In COPAYMENT, the cost to play lottery B is decreased by $20 \%$ from 1 Taler to 0.8 Taler in periods 7 to 12 . In these periods, subjects are in the domain of gains if they constantly choose lottery B and have not

21 lost a lottery in a previous period. Finally, in BONUS, the subjects are credited a bonus payment 22 amounting to 0.5 Taler after every third period, i.e. in periods $3,6,9$ and 12 . All the payments are only provided when subjects are still able to decide between the two lotteries and have not

$24 \quad$ lost a lottery in a previous period. 
1 The experiment was conducted in September 2011, July 2012 and October 2012 in the

2 Economic Experimental Laboratory at a middle-sized European University. Subjects were

3 recruited by the online recruiting system ORSEE (Greiner, 2004) from a pool of approx. 1,800

4 voluntary students from different fields of study, who are enrolled as prospective participants

5 in economic experiments. In total, 12 sessions were conducted with four sessions for each of

6 the three financial incentive treatments, respectively. All in all, 322 subjects participated with

7102 subjects in DEPOSIT, 110 subjects in COPAYMENT and 110 subjects in BONUS,

8 respectively. Participation was restricted to one session only. The experiment was programmed

9 and conducted with the software zTree (Fischbacher, 2007). As soon as the subjects arrived at

10 the Lab, they were asked to randomly draw a number from a box and were told to sit down at

11 the assigned computer workplace in a cubicle detached from each other ensuring complete

12 anonymity. In each session, the subjects received the same introductory talk and were told not to communicate during the complete session. Then, the written instructions were handed out and the subjects had ten minutes time to read them and ask questions in private to clarify any misunderstandings. The instructions of the original experiment BASE and the experimental treatments DEPOSIT, COPAYMENT and BONUS can be found in Appendix C. The instructions were written in a context-free manner so that no associations with medical treatments, drug intake etc. could emerge which might influence subjects' decisions in an uncontrolled way. In the instructions, subjects were assured that all decisions were made anonymously, so that neither the experimenter nor other participants got to know the identity

21 of the subject who made a specific decision. Each subject had to decide solely for herself and was not informed about the decisions of others. Furthermore, the subjects were informed that their payoff was given to them anonymously and that their payoff did not depend on the decisions of the other subjects. At the end of the experiment, the subjects were asked to fill out a questionnaire which consisted of two parts. In the first part, risk preferences were elicited 
1 using an incentivized version of the lottery choice framework by Dohmen et al. (2010) followed

2 by an unpaid second part where subjects were asked questions mainly about their socio3 economic background such as age, gender and field of study. Each session lasted for about one

4 hour and subjects earned on average 10.58 Taler. At the end of each experimental session, the 5 amount of Taler was converted into Euro and paid to subjects along with a show-up fee of $6 € 2.50$, so that on average subjects received approximately $€ 18.50$ (roughly 23 USD at that time).

7

8

\section{Results}

\section{Descriptive Statistics}

Table 1 shows the distribution of choices concerning the lotteries A and B and the corresponding drop-out and "survival" rates for different periods for all financial intervention treatments. Of the 322 subjects who participated in one of the three treatments, the vast majority of roughly $80 \%$ started with lottery B in the first period of the investment plan after completing the slider task in the working stage. Considering that the risk of dropping out of the experiment accumulates with each further decision, the choice of lottery B in all but the last period serves as a dominating strategy for risk-neutral agents with the aim to maximize their payoff in the experiment. The latter requires staying in the experiment for as long as possible. In fact, when lottery B was chosen, the average rate of dropping out of the experiment at any of the 12 decisions was $67.44 \%$ compared with a drop-out rate of $89.00 \%$ when subjects started with lottery A. Looking at this result from the opposite perspective and thus determining how many subjects on average were able to make a choice up to the periods $3,6,9$ and 12 , we see that subjects who constantly chose lottery B had a higher chance of winning the lotteries and staying in the experiment longer than those subjects who opted for lottery A. The average survival rate over the periods keeps decreasing in steps of roughly $25 \%$ for subjects who play lottery A, whereas lottery B players on average had a $16 \%$ higher chance of surviving these periods. 
1 Roughly $32 \%$ of subjects who started with lottery B won all the 12 consecutive lotteries

2 compared with only $11 \%$ of subjects who started with lottery A. Similar to the findings reported

3 in Djawadi et al. (Djawadi and Fahr, R., Turk, R., 2014) the observed behavioral pattern of each

4 experimental treatment does not follow rational choice theory. As can been seen from Table 1

5 only a fraction of subjects chooses the lotteries according to rational choice theory. Rather, the

6 majority of subjects either switch far earlier to lottery A or stay longer with lottery B, supporting

7 the conjecture that judgment biases lead to deviations from choice behavior predicted by

8 standard economic theory.

Table 1: Summary statistics about the distribution of the lottery choices A (equivalent to non-persistent behavior) and B (equivalent to persistent behavior) with corresponding drop-out and survival rates. Percentage of subjects switching from B to A according to rational choice theory.

\section{$<$ Insert Table 1 about here>}

\section{Comparison of Persistence Behavior}

We compare the persistence rate curve of BASE with the corresponding curves of DEPOSIT, COPAYMENT and BONUS respectively. We define the persistence rate as the ratio of lottery B over lottery A choices made by subjects per period, and examine how long in terms of periods subjects continued with therapy over the course of the 12 periods. Consistent with the analysis of Djawadi et al. (Djawadi and Fahr, R., Turk, R., 2014), we only consider those subjects who started with lottery B and switch at most once from lottery B to lottery A either until they drop out of the experiment or until the end of the investment plan.

In fact, $91 \%(88 \%, 92 \%, 94 \%)$ of subjects starting with lottery B in BASE (DEPOSIT, COPAYMENT, BONUS) switch at most once to lottery A and keep choosing this option either until they drop out of the experiment or until the end of the investment plan. The idea is that these subjects correspond to patients who agreed upon medical treatment in the beginning and might discontinue with therapy until the end of the medical treatment. As subjects can drop out of the experiment when losing a lottery, not all individual decisions can be observed throughout 
1 the 12 periods. We therefore determine the potential difference in persistence by using the Log-

2 Rank Test which is commonly used in survival analysis when censored data are present (Lee and Wang, 1992). Figures 2, 3 and 4 show the persistence rate curves as so called Kaplan-Meier estimates which are evaluated by the Log-Rank Test.

5

Figure 2: Kaplan-Meier estimates of the persistence rate in BASE and DEPOSIT

$<$ Insert Figure 2 about here $>$

As can been seen in Figure 2, persistence rates are higher in DEPOSIT compared to BASE only after period 8. This finding indicates that a higher proportion of subjects switched earlier to lottery A compared to BASE when they were in the domain of losses. As soon as the losses were compensated in period 9 , the additional bonus of 0.5 Taler led the remaining subjects to comply more compared to BASE until the end of the time horizon. Thus, we do not find any statistical difference in persistence behavior between DEPOSIT and BASE over all periods (Log-Rank Test Chi-Square value: 0.30, 1-sided, $\mathrm{p}=0.293$ ). Therefore, we cannot support our first hypothesis that extending the phase in which subjects are still in the domain of losses, as incorporated in DEPOSIT, will lead subjects to continue longer with therapy compared to the baseline treatment.

In COPAYMENT, we reduced the expected costs of playing lottery B in periods where subjects have compensated all their previous losses. Figure 3 shows that persistence behavior in BASE and COPAYMENT is almost equally high up to period 8. As predicted by the value function, subjects having now offset their losses, value future gains of continuing with therapy to a lower extent and start switching to the more risky lottery A. However, this decline in persistence in the second half of the decision sequence is steeper in BASE than in COPAYMENT. Hence, the cost intervention in COPAYMENT led a higher proportion of subjects to weigh the benefits over costs in favor of lottery B and, with regard to the complete investment plan, to a significant 
1 increase in persistence compared with BASE (Log-Rank Test Chi Square value: 3.81, 1-sided, $2 \mathrm{p}=0.025)$.

3 In the last financial incentive scheme, BONUS, we provide a bonus payment to the subjects

4 after each third period. BONUS is designed to narrow down the possible choice set, thus leading

5 subjects to take decisions more aligned with rational choice theory.

6

Figure 3: Kaplan-Meier estimates of the persistence rate in BASE and COPAYMENT

$$
<\text { Insert Figure } 3 \text { about here }>
$$

As Figure 4 shows, persistence rates between BASE and BONUS are virtually the same until period 3. With only two exceptions in periods 10 and 12, higher persistence rates can only be observed in BASE. Thus, over all periods we do not find any statistical difference in persistence behavior between BASE and BONUS, rejecting our last hypothesis that choice bracketing will lead subjects to more rational choices and equivalently to more persistence behavior (Log-Rank Test Chi Square value: 0.00, 1-sided, $\mathrm{p}=0.492$ ).

Figure 4: Kaplan-Meier estimates of the persistence rate in BASE and BONUS

$<$ Insert Figure 4 about here $>$

\section{Cost Effectiveness of the Different Financial Incentive Schemes}

We analyze the cost effectiveness of the different financial incentive schemes by evaluating how many periods more subjects complied compared with BASE and how much money in turn was additionally paid to them. We only include those subjects of whom we have complete data, so that the analysis represents a lower bound. For BASE and the single financial interventions, Figure 5 shows the distribution of periods up to which the subjects were persistent by choosing lottery B constantly before switching to lottery A. In all financial intervention treatments, the 
1 median subject was persistent until period 10 which is one period more than in BASE. In line

2 with the findings from the persistence curve analysis, the greater dispersion of persistent periods

3 in DEPOSIT and BONUS makes this difference statistically zero. When inspecting payments

4 to subjects as a measure for costs, we paid subjects in DEPOSIT on average $1 \%$ less and in

5 BONUS on average $10 \%$ more than in BASE. For BONUS, this markup in subjects' payments

6 appears to be a bad investment, seen as the same persistence rates, yet with higher costs, are

7 observed. In COPAYMENT, direct payments to subjects are roughly 9\% more than in BASE.

8 In contrast to BONUS, these additional costs are profitable in terms of additional persistent

9 periods. From Figure 5 and the results of the previous section, it becomes evident that the

10 distribution of persistent periods in COPAYMENT is skewed to the left, meaning that more

11 persistent periods are at the end of the decision sequence. Hence, we have strong indication that

12 subjects are persistent on average one additional period more than in BASE which amounts to 13 a relative increase of $9 \%$.

Figure 5: Median and variance of persistence across treatments

$<$ Insert Figure 5 about here>

Effect of Risk Preferences on Choice Behavior

As discussed in the experimental procedure, individual risk preferences were elicited by the lottery choice framework of Dohmen et al. (2010). In each session, we paid two randomly chosen subjects according to one randomly chosen row of their lottery table in order to provide incentives for truthfully reporting individual risk preferences. The row of the table, in which subjects switch from the 50\%-chance lottery to the safe option, proxies the subjects' willingness to take risks. The later the switching point, the more risk seeking the subject is. Similar to the analysis of the main experiment, we only include subjects who have at most one switching point 
1 in the table and thus monotonic risk preferences. As can be seen from Table 2, more than $96 \%$

2 of the subjects have at most only one switching point in the lottery table. Following the

3 literature, we categorize subjects according to their switching point into four risk categories

4 ranging from risk-averse, slightly risk-averse, risk neutral to risk-seeking. By using maximum

5 likelihood estimation to derive the individual's degree of risk aversion, we ensure that our

6 grouping is in line with similar studies using this or related lottery choice frameworks (for

7 details see $[63,69])$. Table 2 shows the results of our grouping procedure. In line with the

8 literature, the estimated r-value, which captures the degree of risk-aversion, allowed

9 categorizing the subjects seen in the table so that we are confident that our sorting procedure is

10 valid. We pool the data over risk preferences because there is no significant difference in the

11 distribution of risk categories across each experimental treatment (Jonckheere-Terpstra Test J-

12 value: $-1.124,2$-sided, $\mathrm{p}=0.2612$ ).

13

14

15

16

Table 3: Distribution of risk categories

$$
<\text { Insert Table } 2 \text { about here> }
$$

In analogy with the previous analysis, we restrict our sample to those subjects of whom we have complete data in the main experiment and investigate whether the timing of switching from lottery B to lottery A is related to the degree of risk aversion. In fact, we find that subjects who exhibit more risk aversion choose more often lottery B as safer option in the decision sequence compared with those subjects who are more risk-seeking and tend to switch earlier to the more risky lottery A (J-T Test J-value: -1.768, 1-sided, $\mathrm{p}=0.039)$. Thus, we find support for our hypothesis that risk preferences matter when making decisions under risk and uncertainty in this experimental setting, as observed persistence behavior is consistent with the underlying individual risk profile. 


\section{Discussion}

2 The current study uses the procedure of behavioral economic engineering to develop and test

3 three different financial incentive schemes aimed at improving persistence behavior. Drawing

4 on theories from behavioral economics and the conceptual framework of medical non-

5 persistence, loss aversion and the evaluation of future utility gains relative to a reference point

6 are decisive for the individual decision to discontinue with therapy. Based on this knowledge,

7 three financial incentive schemes grounded in concepts of mental accounting, prospect theory

8 and choice bracketing are elaborated. Subsequently, their effectiveness on changing medication

9 taking behavior is investigated under the same controlled experimental conditions, allowing for

10 clear causal inferences on observed behavior. We design a randomized laboratory experiment

11 in which participants decide in analogy to an investment plan between persistence and non-

12 persistence. The economic consequences as trade-off between benefits and costs for persistence behavior and the entailed risks of suffering a medical relapse are modeled as monetary lotteries which participants are asked to choose between in each period.

We find that a financial incentive scheme based on prospect theory significantly increases persistence behavior. By lowering the costs of persistence in situations in which losses have been compensated, the economic gain of being persistent remains attractive and leads subjects to significantly continue longer with therapy compared to the baseline experiment with no incentives at all. Referring to medical treatments, this finding implies that an incentive program of lowering copayments of the medicine prescribed to the patients during the course of the treatment is an effective way in improving persistence behavior. Most co-payment support is currently provided during the domain of losses (treatment initiation) and co-payments often peak during the course of the therapy in periods where subjects have compensated their previous losses, e.g. as in the "donut hole". 
1 In contrast to these results, we do not find any change in persistence when we use a deposit

2 contract to increase loss aversion in the beginning of a treatment or through the use of a bonus

3 system aimed at enhancing rational choice behavior. Behavioral deposits and bonuses represent

4 a widely used incentive type to influence medication taking behavior and patient health

5 behavior.

6 The present study is of course limited in its scope and institutional environment. In addition to

7 the need for more evaluations of other financial incentive schemes, a further interesting and

8 important aspect would be to investigate how strong patients react when once-established

9 financial incentives are withdrawn during the course of the treatment. This behavioral pattern

10 would certainly be very informative for the debate about short vs. long-term effects of financial

11 incentives. As risk preferences play an important role in the decision-making process continue

12 or discontinue with therapy, patients' personal attributes and other potential covariates such as habits and personal experience have to be considered and their effect on the individual hazard

14 of medical non-persistence investigated.

While we have demonstrated how financial incentives can be calibrated and compared under controlled conditions, our findings have to be interpreted with care. Our randomized experiment was conducted following the standards of experimental economics as a computer-assisted laboratory experiment with students as subjects embedded in an artificial environment for a limited time frame. While this study has served as a first proof of concept of a scalable and affordable way of incentive design and calibration, the external validity needs to be

21 demonstrated. We expect to be able to demonstrate validity as several studies about health 22 behavior and preferences show that decisions of students over abstract goods are not necessarily that much different from the patient population and their commodities under interest. For example, Bleichrodt et al. (Bleichrodt et al., 2005) investigate the trade-off between equity and 
1 an economic laboratory experiment, preferences are elicited both in a sample of Dutch students

2 and in a sample from the general population. No significant differences are observed between

3 the views of the students and of the representative sample of the Dutch population. Bleichrodt

4 et al. (Bleichrodt et al., 2012) examine whether the concentration index which is widely used

5 to measure income-related inequality in health connects with people's preferences about

6 distributions of income and health. They explore the principles of the concentration index by

7 using an economic laboratory experiment with a Dutch student sample. The authors find that

8 socio-demographic characteristics do not have any impact on the results leading to the

9 interpretation that studying the validity of principles of income-related health transfers does not

10 depend on the sample to be used.

11 A scalable way of designing, calibrating and testing behavioral incentives has to be found for

12 broad application in real world which minimizes or completely avoids the need for patient research as ineffective behavioral incentives would potentially negatively impact the utilization

14 of important medication. The results of such research would provide us the components of a screening device which integrates patient characteristics along with situational factors (i.e. the type of disease) and personal judgment biases (i.e. the correct risk assessment for non17 persistence behavior) to clearly estimate the individual hazard of medical non-persistence under economic conditions.

Clinical pilots can then be implemented in such a way that at the start of a medical treatment the best performing financial incentive scheme from laboratory studies is selected. As the

21 effectiveness of these schemes is expected to work the strongest, the obtained results will clarify 22 the role of financial incentives in serving as realizable interventions to successfully combat medical non-persistence. 


\section{Conclusion}

1 Increasing healthcare delivery efficiency and effectiveness is a major public health need in

2 almost all health systems. Improvements are seen as not only being driven by new clinical

3 science, but by scalable and efficient ways to drive behavioral change. Behavioral Economic

4 Engineering built on principles of behavioral economics and behavioral laboratory experiments

5 could finally unlock the treatment persistence dividend and provide a scalable way of designing,

6 calibrating and testing tailored and effective behavioral incentives.

7

\section{Acknowledgement}

9 The research reported in this article is funded by Novartis Pharma AG, Basel, Switzerland.

10 The authors thank participants of the "ISPOR Annual World Meeting 2012" in Washington,

11 DC, the "12th Journées Louis-André Gérard-Varet” held 2013 in Aix-en-Provence, "1st

12 Workshop on Behavioral and Experimental Health Economics" held 2014 in Oslo, the

13 "London Experimental Workshop: Better Policies - Better lives 2015", and in seminars at the

14 University of Paderborn for valuable comments.

15

16

17

18

19

\section{References}

Asch, D.A., Muller, R., Volpp, K.G., 2012. Automated hovering in health care - Watching over the 5,000 hours. New England of Medicine 367 (1), 1-3.

Bleichrodt, H., Doctor, J., Stolk, E., 2005. A nonparametric elicitation of the equity-efficiency trade-off in cost-utility analysis. Journal of Health Economics 24, 655-678.

Bleichrodt, H., Rohde, K., van Ourti, T., 2012. An experimental test of the concentration index. Journal of Health Economics 31, 86-98. 
1 Bolton, G., Greiner, B., Ockenfels, A., 2013. Engineering Trust: Reciprocity in the Production 2 of Reputation Information. Management Scie 59 (2), 268-285.

3 Bolton, G.E., Ockenfels, A., 2012. Behavioral economic engineering. Journal of Economic Psychology 33 (3), 665-676.

Cleemput, I., Kesteloot, K., DeGeest, S., 2002. A review of the literature on the economics of noncompliance. Room for methodological improvement. Health Policy 59 (1), 65-94.

Cramer, J.A., Roy, A., Burrell, A., Fairchild, C.J., Fuldeore, M.J., Ollendorf, D.A., Wong, P.K., 2008. Medication Compliance and Persistence: Terminology and Definitions. Value

Djawadi, B.M., Fahr, R., Turk, R., 2014. Conceptual Model and Economic Experiments to Explain Non-persistence and Enable Mechanism Designs Fostering Behavioral Change.

Frederick, S., 2005. Cognitive Reflection and Decision Making. Journal of Economic Value in Health 17, 814-822.

Dohmen, T., Falk, A., Huffman, D., Sunde, U., 2010. Are Risk Aversion and Impatience Related to Cognitive Ability? American Economic Review 100, 1238-1260.

Donovan, J.L., Blake, D.R., 1992. Patient non-compliance: Deviance or reasoned decisionmaking? In: Social Science \& Medicine. Social Science \& Medicine 34 (5), 507-513.

Fischbacher, U., 2007. z-Tree: Zurich toolbox for ready-made economic experiments. Experimental Economics 10 (2), 171-178. Perspectives 19 (4), 25-42.

Gill, D., Prowse, V., 2012. A Structural Analysis of Disappointment Aversion in a Real Effort Competition. American Economic Review 102 (1), 469-503.

Goeree, J.K., Holt, C., Palfrey, T., 2003. Risk Averse Behavior in Generalized Matching Pennies Games. Games and Economic Behavior 45, 97-113. 
1 Greiner, B., 2004. An Online Recruiting System for Economic Experiments. Kurt Kremer,

2 Volker Macho (Eds.): Forschung und wissenschaftliches Rechnen 2003, GWDG Bericht,

3 Goettingen: Geschichte für Wiss. Datenverarbeitung 63, 79-93.

4 Higgins S. T., Wong, C.J., Badger, G.J., Haug Ogden, D. E., Dantona, R.L., 2000. Contingent

5 Reinforcement Increases Cocaine Abstinence During Outpatient Treatment and 1 Year of

$6 \quad$ Follow-Up. Journal of Consulting and Clinical Psychology 68 (1), 64-72.

7 Hughes, D.A., Bagust, A., Haycox, A., Walley, T., 2001. The impact of non-compliance on

8 the cost-effectiveness of pharmaceuticals. Health Economics 10, 601-615.

9 Kahneman, D., Tversky, A., 1979. Prospect Theory: An Analysis of Decision under Risk.

$10 \quad$ Econometrica 47 (2), 263-292.

11 Kripalani, S., Yao, X., Haynes, B., 2007. Interventions to Enhance Medication Adherence in 12 Chronic Medical Conditions. Archives of Internal Medicine 167, 540-550.

Kullgren, J.T., Troxel, A.B., Loewenstein, G., Asch, D.A., Norton, L.A., Wesby, L., Tao, Y., Zhu, J., Volpp, K.G., 2013. Individual- Versus Group-Based Financial Incentives for Weight Loss. Annals of Internal Medicine 158 (7), 505-514.

Lazear, E.P., 2000. Performance Pay and Productivity. The American Economic Review 90 (5), 1346-1361.

Lee, E.T., Wang, J.W., 1992. Statistical methods for survival data analysis, Fourth edition, Wiley series in probability and statistics. New York.

Loewenstein, G., Brennan, T., Volpp, K.G., 2007. Asymmetric Paternalism to Improve Health Behaviors. JAMA 298 (20), 2415-2417.

Long, J.A., Jahnle, E.C., Richardson, D.M., Loewenstein, G., Volpp, K.G., 2012. Peer Mentoring and Financial Incentives to Improve Glucose Control in African American Veterans. Annals of Internal Medicine 156 (6), 416-424. 
1 Lussier, J.P., Heil, S.H., Mongeon, J.A., Badger, G.J., Higgins, S.T., 2006. A meta-analysis of 2 voucher-based reinforcement therapy for substance use disorders. Addiction 101 (2), 1923203.

4 McDonald, H.P., Garg, A.X., Haynes, R.B., 2002. Interventions to Enhance Patient

Prendergast, C., 1999. The provision of incentives in firms. Journal of Economic Literature 37 (1), 7-63.

Read, D., Loewenstein, G., Rabin, M., 1999. Choice Bracketing. Journal of Risk and Uncertainty 19 (1-3), 171-197.

Roth, A.E., 2002. The Economist as Engineer: Game Theory, Experimentation, and Computation as Tools for Design Economics. Econometrica 70 (4), 1341-1378.

Schmidt, D., Shupp, R., Walker, J.M., Ostrom, E., 2003. Playing safe in coordination games:

Siiskonen, S.J., Breekveldt-Postma, N.S., Vincze, G., Khan, Z.M., Erkens, J.A., Herings, R. M. C., 2007. Higher Persistence with valsartan compared with enalapril in daily practice. Vascular Health and Risk Management 3 (6), 1039-1044.

Straub, P.G., 1995. Risk dominance and coordination failures in static games. The Quarterly Review of Economics and Finance 35 (4), 339-363.

Thaler, R., 1985. Mental Accounting and Consumer Choice. Marketing Science 4 (3), 199214.

Thaler, R., 1999. Mental Accounting matters. Journal of Behavioral Decision Making 12 (3), 183-206. 
1 Thaler, R.H., Johnson, E.J., 1990. Gambling with the House Money and Trying to Break

2 Even: The Effects of Prior Outcomes on Risky Choice. Management Science 36 (6), 6433660.

4 van Wijk, B. L. G., Klungel, O.H., Heerdink, E.R., Boer, A. de, 2005. Rate and determinants of 10-year persistence with antihypertensive drugs. Journal of Hypertension 23 (11),

Vermeire, E., Hearnshaw, H., van Royen, P., Denekens, J., 2001. Patient adherence to treatment: three decades of research. A comprehensive review. Journal of Clinical Pharmacy and Therapeutics 26 (5), 331-342.

Volpp, K.G., John, L.K., Troxel, A.B., Norton, L., Fassbender, J., Loewenstein, G., 2008a. Financial Incentive-Based Approaches for Weight Loss. JAMA 300 (22), 2631-2637.

Volpp, K.G., Loewenstein, G., Troxel, A.B., Doshi, J., Price, M., Laskin, M., Kimmel, S.E.,

World Health Organization (WHO), 2013. Adherence to long-term therapies - Evidence for action. http://www.who.int/chp/knowledge/publications/adherence_full_report.pdf. 
Figures and Tables

Figure 1: The two stages of the experiment and expected persistence behavior

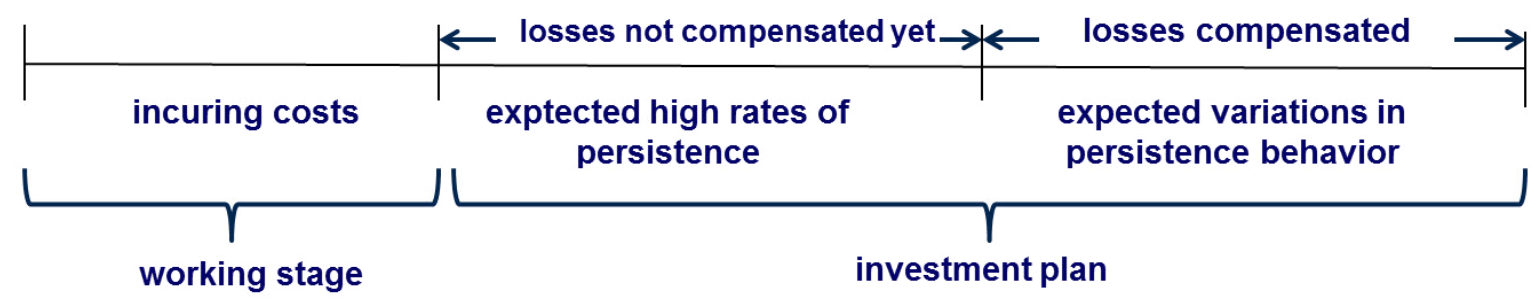

Figure 2: Kaplan-Meier estimates of the persistence rate in BASE and DEPOSIT

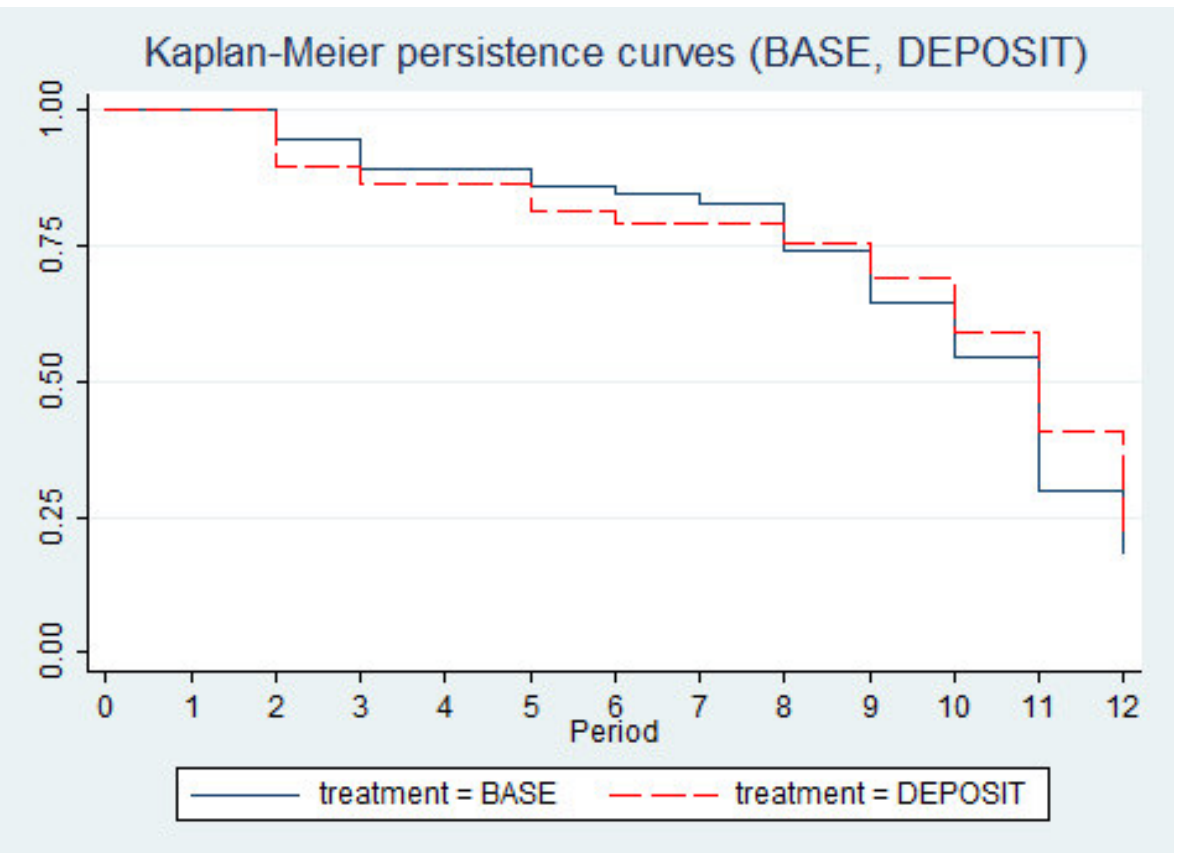

Figure 3: Kaplan-Meier estimates of the persistence rate in BASE and COPAYMENT

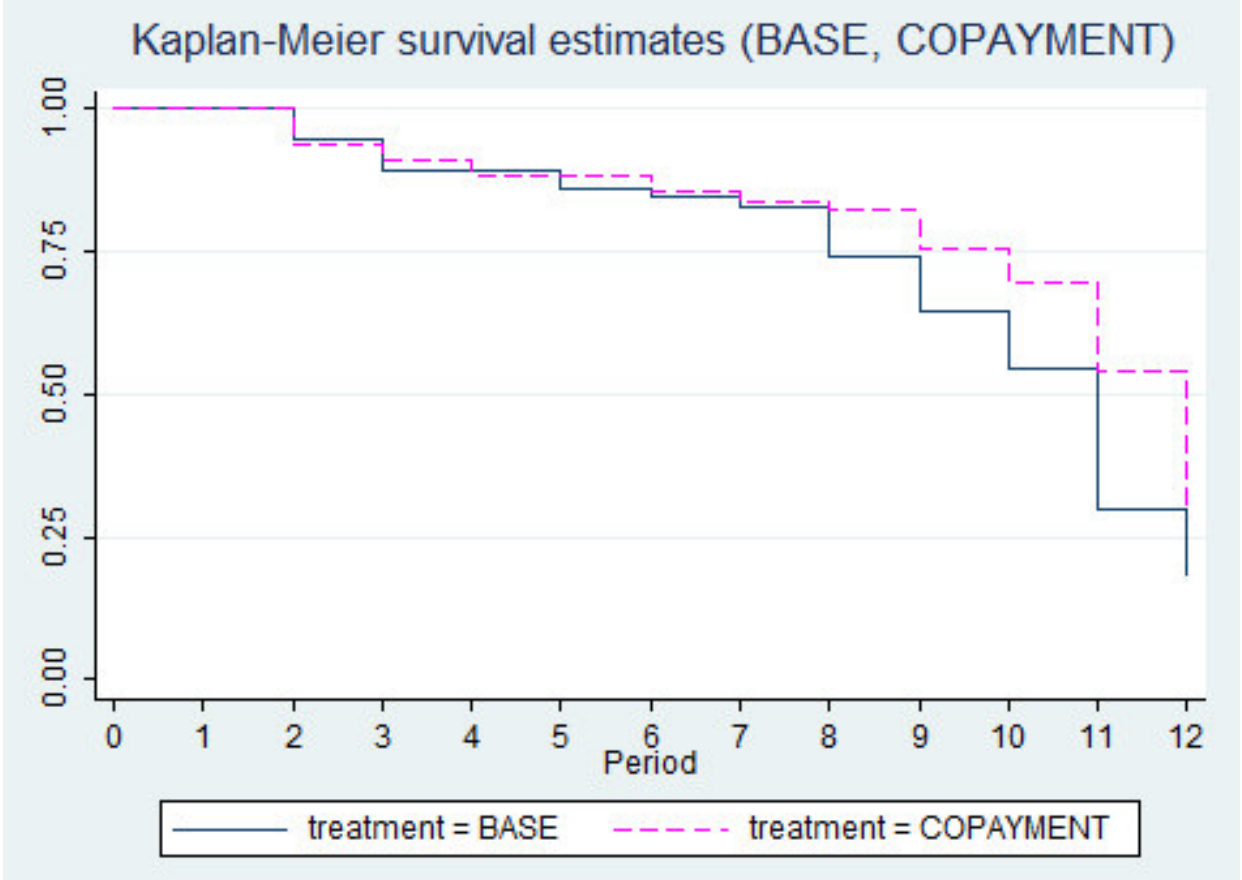


Figure 4: Kaplan-Meier estimates of the persistence rate in BASE and BONUS

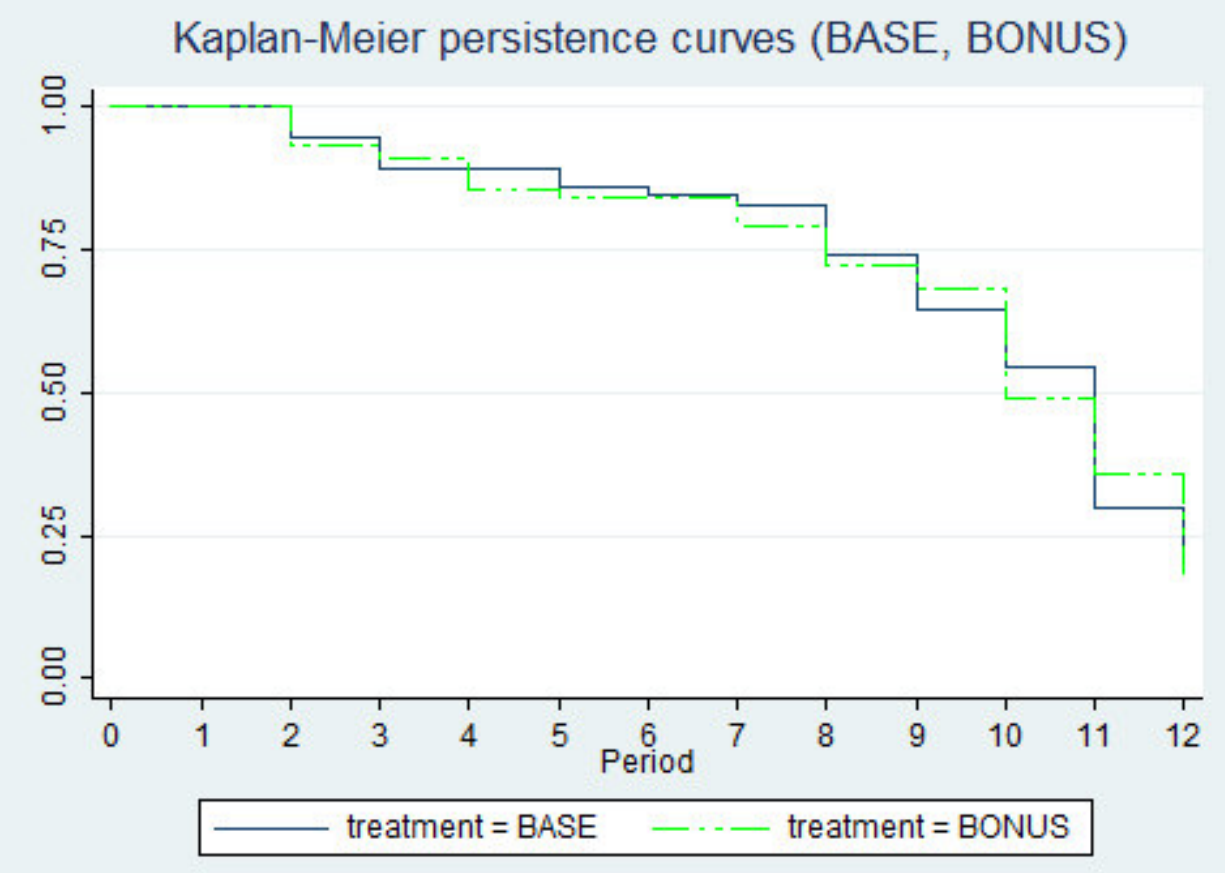

Figure 5: Median and variance of persistence across treatments

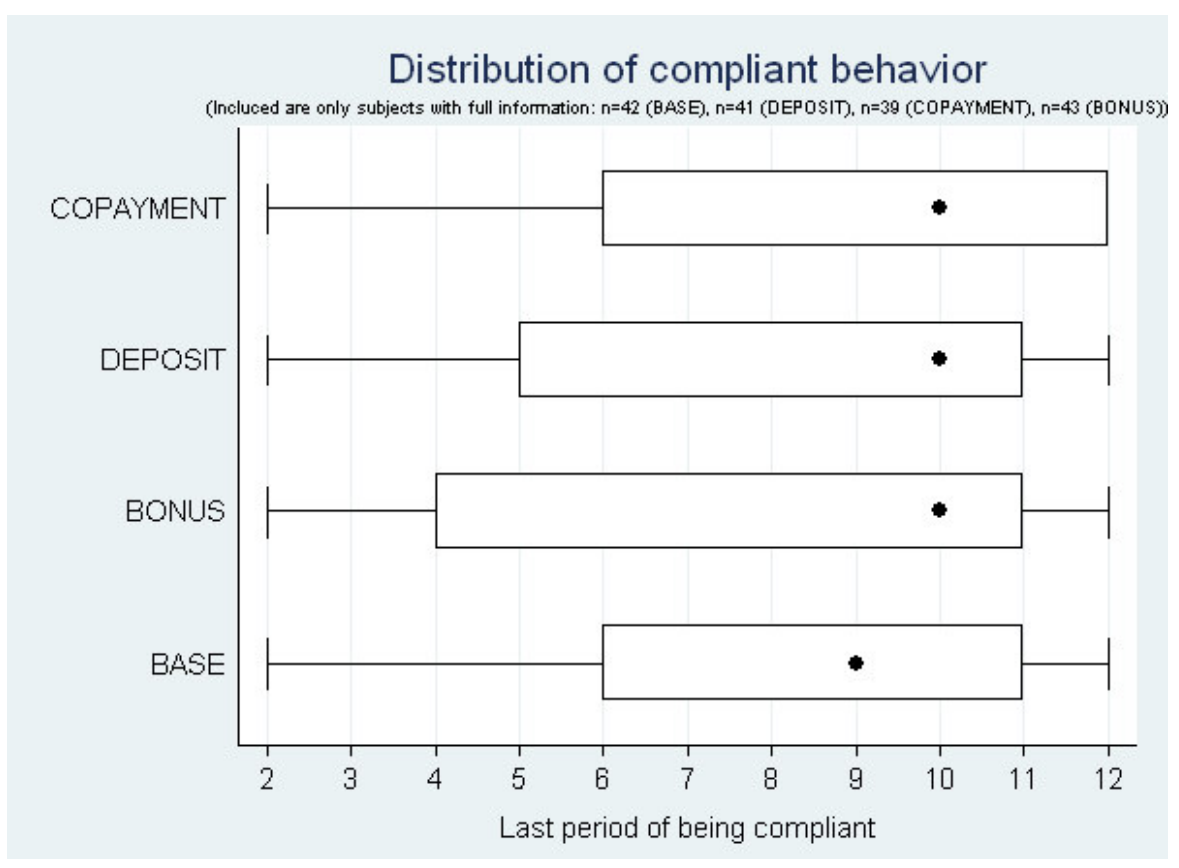


Table 1: Summary statistics about the distribution of the lottery choices A (equivalent to non-persistent behavior) and B (equivalent to persistent behavior) with corresponding drop-out and survival rates. Percentage of subjects switching from B to A according to rational choice theory.

\begin{tabular}{|c|c|c|c|c|c|c|c|c|}
\hline & \multicolumn{2}{|c|}{ DEPOSIT } & \multicolumn{2}{|c|}{ COPAYMENT } & \multicolumn{2}{|c|}{ BONUS } & \multicolumn{2}{|c|}{ Total } \\
\hline of the investment plan & A & B & A & B & A & B & A & B \\
\hline$\%$ subjects & 20.60 & 79.40 & 17.30 & 82.70 & 20.00 & 80.00 & 19.25 & 80.75 \\
\hline$\%$ drop out rate & 85.7 & 59.3 & 84.2 & 62.64 & 90.91 & 73.86 & 87.10 & 65.38 \\
\hline$\%$ survival rate until period 3 & 71.43 & 87.65 & 42.11 & 89.01 & 59.10 & 92.05 & 58.06 & 89.62 \\
\hline$\%$ survival rate until period 6 & 33.33 & 69.14 & 26.32 & 72.53 & 36.36 & 72.73 & 32.26 & 71.54 \\
\hline$\%$ survival rate until period 9 & 19.05 & 55.56 & 21.05 & 59.34 & 31.82 & 51.14 & 24.19 & 57.31 \\
\hline$\%$ survival rate until period 12 & 14.29 & 40.74 & 15.79 & 37.36 & 9.10 & 26.14 & 12.90 & 34.62 \\
\hline \multicolumn{9}{|l|}{ Switching from B to A } \\
\hline$\%$ subjects switching on time & \multirow{2}{*}{\multicolumn{2}{|c|}{$\begin{array}{l}21.95 \\
56.09\end{array}$}} & \multicolumn{2}{|c|}{20.51} & \multicolumn{2}{|c|}{13.95} & \multicolumn{2}{|c|}{18.81} \\
\hline$\%$ subjects switching earlier & & & \multicolumn{2}{|c|}{51.28} & \multicolumn{2}{|c|}{69.77} & \multicolumn{2}{|c|}{59.05} \\
\hline$\%$ subjects switching later & \multicolumn{2}{|c|}{21.95} & \multicolumn{2}{|c|}{28.21} & \multicolumn{2}{|c|}{16.28} & \multicolumn{2}{|c|}{22.15} \\
\hline
\end{tabular}

Table 2: Distribution of risk categories

\begin{tabular}{|lccccc|}
\hline risk category & DEPOSIT & COPAYMENT & BONUS & total (\%) & r-value \\
\hline \hline risk averse & $51(52.04)$ & $42(39.25)$ & $38(36.54)$ & $131(42.39)$ & 0.603 \\
slightly risk averse & $30(30.61)$ & $40(37.38)$ & $38(36.54)$ & $108(34.95)$ & 0.379 \\
risk neutral & $13(13.27)$ & $21(19.63)$ & $22(21.15)$ & $56(18.12)$ & 0.092 \\
risk seeking & $4(4.08)$ & $4(3.74)$ & $6(5.77)$ & $14(4.53)$ & -1.250 \\
total $(\%)$ & $98(31.71)$ & $107(34.63)$ & $104(33.66)$ & $309(100)$ & \\
\hline
\end{tabular}

Note: 13 out of 322 subjects were excluded from the analysis because their switching behavior seems to be random. 


\section{Appendix}

A. Screenshots of the displays in the working stage and the lottery stage

Figure A.1: Screenshot of the slider task in the working stage

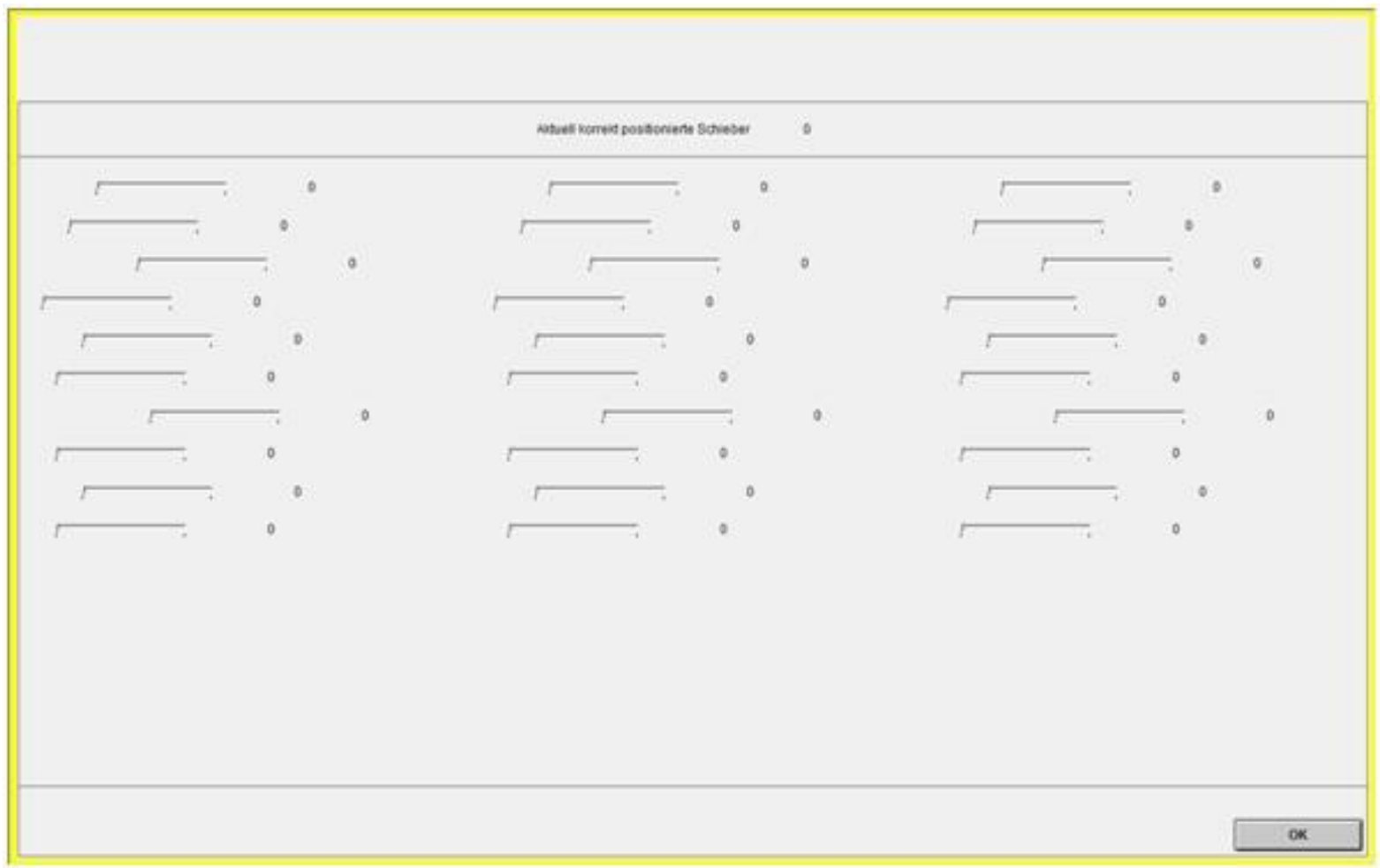


Figure A.2: Choice display in the lottery stage

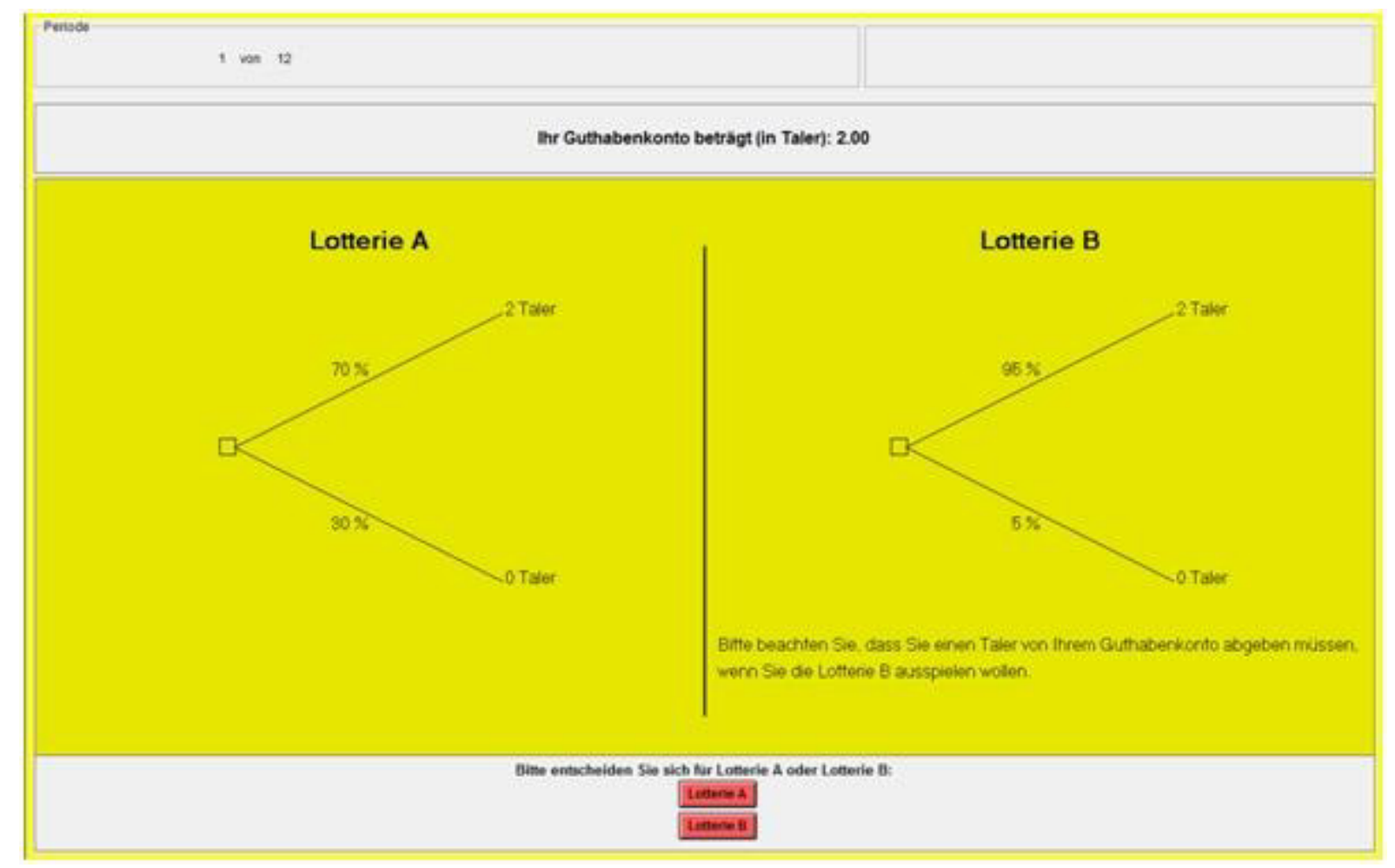

\section{B: Optimal decision sequence in the investment plan}

We derive the rational choice behavior for a risk-neutral, expected utility maximizer who makes 12 consecutive decisions over the lotteries A and B. Tables B.1-B.3 summarize for all periods and for all financial intervention treatments DEPOSIT, COPAYMENT and BONUS which lottery to chose to maximize expected utility. Recall from the different designs that in DEPOSIT subjects have to pay an additional amount of 0.5 Taler for periods 1-6 which are subsequently paid back in periods 7-12, irrespective of the chosen lottery. In COPAYMENT the amount to invest in lottery B decreases by $20 \%$ in periods 7-12. Lastly, a bonus payment of 0.5 Taler is paid to subjects in periods 3, 6, 9 and 12 of BONUS irrespective of the chosen lottery if subjects have not been already dropped out of the experiment. As can be seen by the numbers the dominating strategy to maximize expected utility in each of the three intervention treatments is to chose lottery B until the second last period and only switch to lottery A in the very last period. 
Table B.1: Expected Value (EV) and expected choice which lottery to choose to maximize utility in each of the periods of the financial intervention treatment DEPOSIT.

\begin{tabular}{clllc}
\hline $\begin{array}{c}\text { \# of periods } \\
\text { remaining }\end{array}$ & $\begin{array}{l}\text { Current } \\
\text { Period }\end{array}$ & EV of choosing lottery A & EV of choosing lottery B & Expected Choice \\
\hline 0 & 12 & $0.7^{*} 2+0.5=1.90$ & $0.95^{*} 1+0.5=1.45$ & $\mathrm{~A}$ \\
1 & 11 & $0.7^{*}(2+1.90)+0.5=3.23$ & $0.95^{*}(1+1.90)+0.5=3.26$ & $\mathrm{~B}$ \\
2 & 10 & $0.7 *(2+3.26)+0.5=4.18$ & $0.95^{*}(1+3.26)+0.5=4.55$ & $\mathrm{~B}$ \\
3 & 9 & $0.7 *(2+4.55)+0.5=5.08$ & $0.95^{*}(1+4.55)+0.5=5.77$ & $\mathrm{~B}$ \\
4 & 8 & $0.7 *(2+5.77)+0.5=5.94$ & $0.95^{*}(1+5.77)+0.5=6.93$ & $\mathrm{~B}$ \\
5 & 7 & $0.7 *(2+6.93)+0.5=6.75$ & $0.95 *(1+6.93)+0.5=8.03$ & $\mathrm{~B}$ \\
6 & 6 & $0.7 *(2+8.03)-0.5=6.52$ & $0.95^{*}(1+8.03)-0.5=8.08$ & $\mathrm{~B}$ \\
7 & 5 & $0.7 *(2+8.08)-0.5=6.56$ & $0.95 *(1+8.08)-0.5=8.13$ & $\mathrm{~B}$ \\
8 & 4 & $0.7 *(2+8.13)-0.5=6.60$ & $0.95 *(1+8.13)-0.5=8.17$ & $\mathrm{~B}$ \\
9 & 3 & $0.7 *(2+8.17)-0.5=6.62$ & $0.95 *(1+8.17)-0.5=8.21$ & $\mathrm{~B}$ \\
10 & 2 & $0.7 *(2+8.21)-0.5=6.65$ & $0.95 *(1+8.21)-0.5=8.25$ & $\mathrm{~B}$ \\
11 & 1 & $0.7 *(2+8.25)-0.5=6.68$ & $0.95 *(1+8.25)-0.5=8.29$ & $\mathrm{~B}$ \\
\hline
\end{tabular}

Table B.2: Expected Value (EV) and expected choice which lottery to choose to maximize utility in each of the periods of the financial intervention treatment COPAYMENT

\begin{tabular}{clllc}
\hline $\begin{array}{c}\text { \# of periods } \\
\text { remaining }\end{array}$ & $\begin{array}{l}\text { Current } \\
\text { Period }\end{array}$ & EV of choosing lottery A & EV of choosing lottery B & Expected Choice \\
\hline 0 & 12 & $0.7^{*} 2=1.40$ & $0.95^{*} 1.2=1.14$ & $\mathrm{~A}$ \\
1 & 11 & $0.7^{*}(2+1.4)=2.38$ & $0.95^{*}(1.2+1.4)=2.47$ & $\mathrm{~B}$ \\
2 & 10 & $0.7^{*}(2+2.47)=3.13$ & $0.95^{*}(1.2+2.47)=3.49$ & $\mathrm{~B}$ \\
3 & 9 & $0.7^{*}(2+3.49)=3.84$ & $0.95^{*}(1.2+3.49)=4.46$ & $\mathrm{~B}$ \\
4 & 8 & $0.7^{*}(2+4.46)=4.52$ & $0.95^{*}(1.2+4.46)=5.38$ & $\mathrm{~B}$ \\
5 & 7 & $0.7^{*}(2+5.38)=5.17$ & $0.95^{*}(1.2+5.38)=6.25$ & $\mathrm{~B}$ \\
6 & 6 & $0.7^{*}(2+6.25)=5.78$ & $0.95^{*}(1+6.25)=6.88$ & $\mathrm{~B}$ \\
7 & 5 & $0.7^{*}(2+6.88)=6.22$ & $0.95^{*}(1+6.88)=7.49$ & $\mathrm{~B}$ \\
8 & 4 & $0.7 *(2+7.49)=6.64$ & $0.95^{*}(1+7.49)=8.06$ & $\mathrm{~B}$ \\
9 & 3 & $0.7 *(2+8.06)=7.04$ & $0.95^{*}(1+8.06)=8.61$ & $\mathrm{~B}$ \\
10 & 2 & $0.7^{*}(2+8.61)=7.43$ & $0.95^{*}(1+8.61)=9.13$ & $\mathrm{~B}$ \\
11 & 1 & $0.7 *(2+9.13)=7.79$ & $0.95^{*}(1+9.13)=9.62$ & $\mathrm{~B}$ \\
\hline
\end{tabular}

Table B.3: Expected Value (EV) and expected choice which lottery to choose to maximize utility in each of the periods of the financial intervention treatment BONUS

\begin{tabular}{clllc}
$\begin{array}{c}\text { \# of periods } \\
\text { remaining }\end{array}$ & $\begin{array}{l}\text { Current } \\
\text { Period }\end{array}$ & EV of choosing lottery A & EV of choosing lottery B & Expected Choice \\
\hline 0 & 12 & $0.7 * 2+0.5=1.90$ & $0.95^{*} 1+0.5=1.45$ & $\mathrm{~A}$ \\
1 & 11 & $0.7 *(2+1.90)=2.73$ & $0.95^{*}(1+1.90)=2.76$ & $\mathrm{~B}$ \\
2 & 10 & $0.7 *(2+2.76)=3.33$ & $0.95^{*}(1+2.76)=3.57$ & $\mathrm{~B}$ \\
3 & 9 & $0.7 *(2+3.57)+0.5=4.40$ & $0.95 *(1+3.57)+0.5=4.84$ & $\mathrm{~B}$ \\
4 & 8 & $0.7 *(2+4.84)=4.79$ & $0.95 *(1+4.84)=5.55$ & $\mathrm{~B}$ \\
5 & 7 & $0.7 *(2+5.55)=5.28$ & $0.95 *(1+5.55)=6.22$ & $\mathrm{~B}$ \\
6 & 6 & $0.7 *(2+6.22)+0.5=6.25$ & $0.95 *(1+6.22)+0.5=7.36$ & $\mathrm{~B}$ \\
7 & 5 & $0.7 *(2+7.36)=6.55$ & $0.95 *(1+7.36)=7.94$ & $\mathrm{~B}$ \\
8 & 4 & $0.7 *(2+7.94)=6.96$ & $0.95 *(1+7.94)=8.49$ & $\mathrm{~B}$ \\
9 & 3 & $0.7 *(2+8.49)+0.5=7.85$ & $0.95 *(1+8.49)+0.5=9.52$ & $\mathrm{~B}$ \\
10 & 2 & $0.7 *(2+9.52)=8.06$ & $0.95 *(1+9.52)=9.99$ & $\mathrm{~B}$ \\
11 & 1 & $0.7 *(2+9.99)=8.40$ & $0.95 *(1+9.99)=10.44$ & $\mathrm{~B}$ \\
\hline
\end{tabular}

\section{C: Instructions of the experiments}

\section{C1: Instructions of original experiment BASE (translated from German)}

- For the course of the experiment, all amounts of money will be stated in the fictive currency "Taler".

- The experiment consists of two stages. 
- Your payment is in no stage of the experiment dependent on the decisions of the other participants.

- At the end of the experiment we would like you to fill out a questionnaire. For this you will get a short set of instructions as soon as the experiment has ended. The answers in this questionnaire do not influence your payment you will receive from this experiment.

\section{Stage I - Procedure}

- Take as much time as you need for this stage.

- In this stage you must work on a task which is to place 30 little sliders in the middle, exactly on the target position 50, with the computer mouse (see illustration). The order of positioning the sliders does not matter. Only the amount of correctly placed sliders counts.

a) Initial position

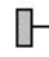

- This task is worth 8 Talers. Of these 8 Talers, you must pay 6 Talers in order to take part in the second stage of the experiment. The remaining 2 Talers will be added to your account as credit.

- As soon as you successfully finish this task, you will begin with stage II.

\section{Stage II - Procedure}

- This stage consists of 12 periods.

- You have 2 Talers credit in your account.

- In every period, you choose between two lotteries, called lottery A and lottery B.

- You will be shown the following screen with the choices:

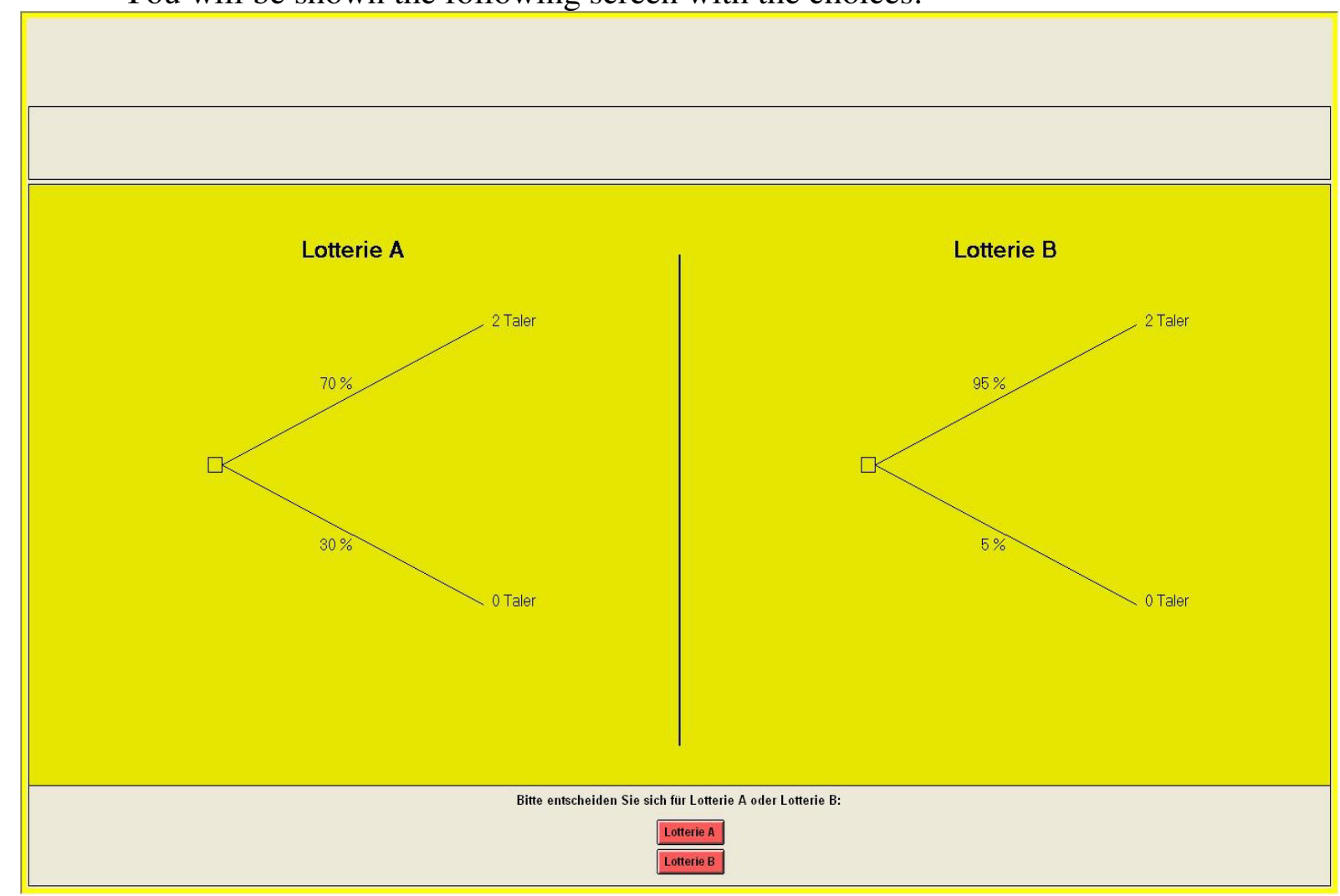


- Playing lottery A, you have the possibility to win 2 Talers with a probability of $70 \%$ and 0 Talers with a probability of $30 \%$.

- Playing lottery B, you have the possibility to win 2 Talers with a probability of $95 \%$ and 0 Talers with a probability of $5 \%$.

- You will not be allowed to participate in any of the following periods, should you in any period win 0 Talers in the chosen lottery.

- In order to play the Lottery B, you must pay a fee of 1 Taler.

- As soon as you have chosen a lottery in one period, it is played as follows:

○ 20 sliders will appear on the screen.

○ In lottery A, 14 of the 20 sliders (70\%) lead to a profit of 2 Talers, if they are positioned on the target position of 50 . The 14 out of the 20 sliders which lead to a profit of 2 Talers are determined by chance. It is your task to position exactly one slider of all 20 sliders on the target position of 50. If you hit one of the 14 sliders, which lead to a profit of 2 Talers, these will be added to your account. In the case you do not hit any of the 14 sliders, you will not be given any Talers, in addition to not being allowed to take part in any lottery in any following period.

- In lottery B, 19 of the 20 sliders (95\%) lead to a profit of 2 Talers, if they are positioned on the target position of 50 . The 19 out of the 20 sliders which lead to a gain of 2 Talers are determined by chance. It is your task to position exactly one slider of all 20 sliders on the target position of 50. If you hit one of the 19 sliders, which lead to a profit of 2 Talers, these will be added to your account. In the case you do not hit any of the 19 sliders, you will not be given any Talers, in addition to not being allowed to take part in any lottery in any following period.

- If you win 2 Talers in the lottery A or the lottery B, you once again have the chance to choose between one of the lotteries A or B in the next period. The sliders which lead to the gaining of 2 Talers in either lottery A or B are again determined by chance in the next period. The 2 Talers are then again credited to your account.

- If you win 0 Talers in one period, you are automatically forwarded to a user interface for all the following periods. Here, you will be asked to make some estimations for which you will not get any money. In addition, you are not allowed to take part in any lottery of the following periods. The credit you have earned will remain unchanged for all the following periods.

- After every period you will be informed about your current amount of credit.

\section{Payments:}

- At the end of the experiment, your credit will be exchanged at an exchange rate of 1.50 Euro per 1 Taler. A show-up fee of 2.50 Euro is added to this amount which is then directly paid out to you in cash.

\section{Please note:}

- During the entire experiment, any form of communication is not permitted.

- All mobile phones must be switched off during the complete duration of the experiment.

- The decisions you make within this experiment are anonymous, i.e. none of the other participants gets to know the identity of a person who has made a specific decision.

- The payments are also handled anonymously. No other participant finds out how much money other participants are paid. 
- Please remain seated until the end of the experiment. You will be called forward for your payment through your seat number.

\section{Good luck and thank you for your participation in this experiment!}

\section{C2: Instructions of the experimental treatments DEPOSIT,COPAYMENT and BONUS ${ }^{1}$ (translated from German)}

- For the course of the experiment, all amounts of money will be stated in the fictive currency "Taler".

- The experiment consists of two stages.

- Your payment is in no stage of the experiment dependent on the decisions of the other participants.

- At the end of the experiment we would like you to fill out a questionnaire. For this you will get a short set of instructions as soon as the experiment has ended. The answers in this questionnaire do not influence your payment you will receive from this experiment.

\section{Stage I - Procedure}

- Take as much time as you need for this stage.

- In this stage you must work on a task which is to place 30 little sliders in the middle, exactly on the target position 50, with the computer mouse (see illustration). The order of positioning the sliders does not matter. Only the amount of correctly placed sliders counts.

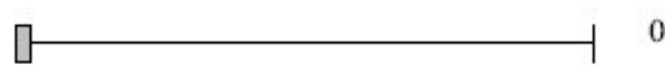

a) Initial position

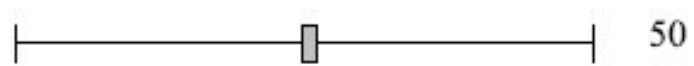

b) target position

- This task is worth 8 Taler. Of these 8 Taler, you must pay 6 Taler in order to take part in the second stage of the experiment. The remaining 2 Taler will be added to your account as credit.

- As soon as you successfully finish this task, you will begin with stage II.

\section{Stage II - Procedure}

- This stage consists of 12 periods.

- You have 2 Taler credit in your account.

- In every period, you choose between two lotteries, called lottery A and lottery B.

- You will be shown the following screen with the choices:

\footnotetext{
${ }^{1}$ Please note: Text passages marked with DEPOSIT \{\} belong to the DEPOSIT treatment, text passages marked with COPAYMENT \{\} belong to the COPAYMENT treatment and text passages marked with BONUS \{\} belong to the BONUS treatment only.
} 


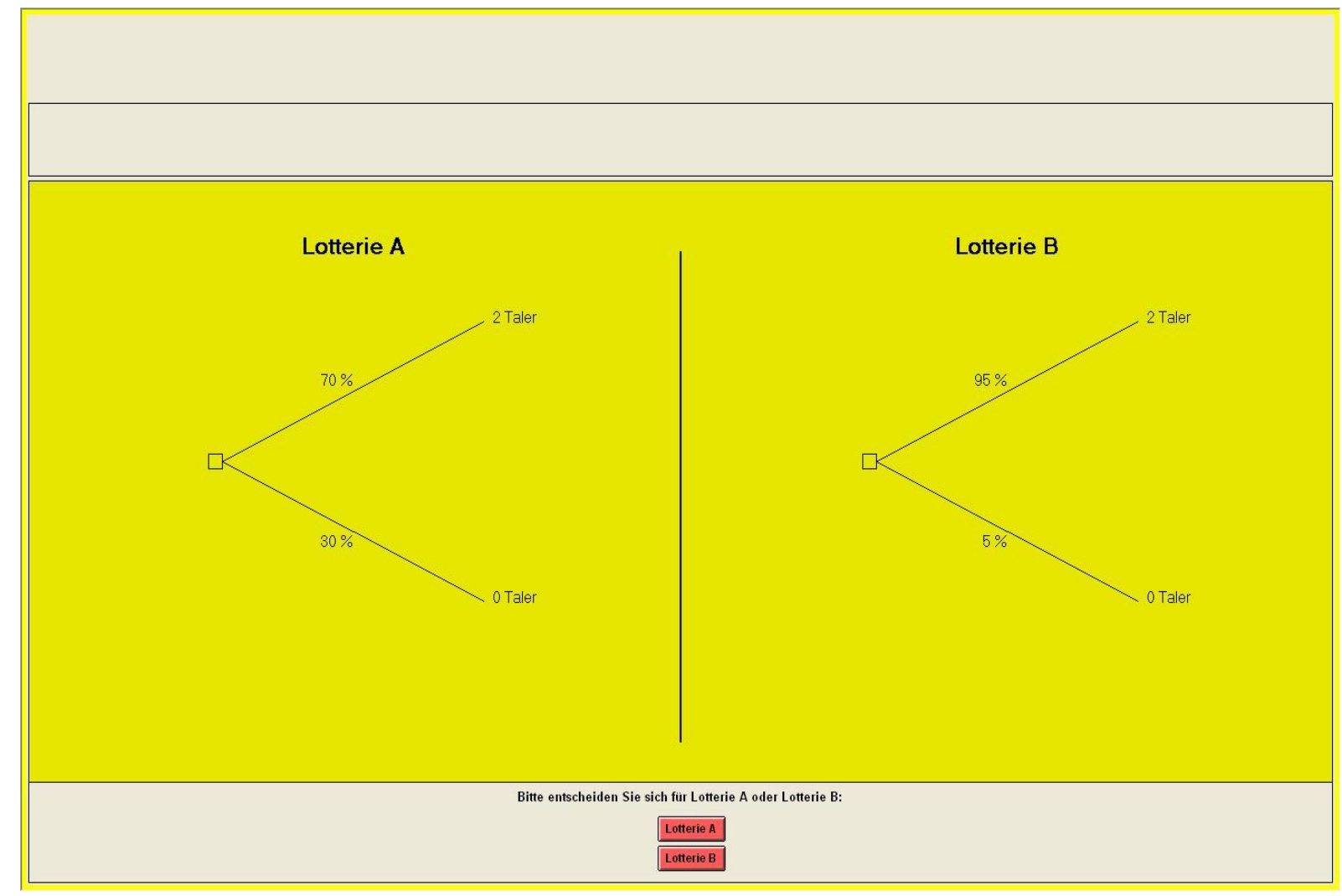

- Playing lottery A, you have the possibility to win 2 Taler with a probability of $70 \%$ and 0 Taler with a probability of $30 \%$.

- Playing lottery B, you have the possibility to win 2 Taler with a probability of $95 \%$ and 0 Taler with a probability of $5 \%$.

- You will not be allowed to participate in any of the following periods, should you in any period win 0 Taler in the chosen lottery.

DEPOSIT: \{

- In order to play the Lottery B, you must pay a fee of 1 Taler

- Independent of your choice of lottery, a participation fee of 0.5 Taler will be charged in each of the periods 1 up to and including 6 . This fee is automatically deducted from your account in each period.

- Independent of your choice of lottery, this participation fee of 0.5 Taler will be added back to your account in each of the periods 7 up to and including 12.

- The deduction of the participation fee of 0.5 Taler from your account in periods 1 to 6 only occurs, if you are still allowed to participate in the lottery of the respective period.

- The repayment of the participation fee of 0.5 Taler to your account in periods 7 to 12 only occurs, if you are still allowed to participate in the lottery of the respective period.\}

\section{COPAYMENT: \{}

- In order to play the Lottery B in the periods 1 up to and including 6, you must pay a fee of 1 Taler. 
- In the periods 7 up to and including 12 , the fee, that must be paid in order to play the Lottery B, will be reduced by $20 \%$. Thus, in order to play the Lottery B in the periods 7 up to and including 12 , you must pay a fee of 0.8 Taler. BONUS: \{

- In order to play the Lottery B, you must pay a fee of 1 Taler.

- Independent of your choice of lottery, a bonus of 0.5 Taler will be credited to your account after each third period.

- This bonus will only be credited to your account in periods 3, 6, 9, and 12 respectively, if you are still allowed to participate in the lottery of the respective period.\}

- As soon as you have chosen a lottery in one period, it is played as follows:

○ 20 sliders will appear on the screen.

○ In lottery A, 14 of the 20 sliders (70\%) lead to a profit of 2 Taler, if they are positioned on the target position of 50 . The 14 out of the 20 sliders which lead to a profit of 2 Taler are determined by chance. It is your task to position exactly one slider of all 20 sliders on the target position of 50. If you hit one of the 14 sliders, which lead to a profit of 2 Taler, these will be added to your account. In the case you do not hit any of the 14 sliders, you will not be given any Taler, in addition to not being allowed to take part in any lottery in any following period.

○ In lottery B, 19 of the 20 sliders (95\%) lead to a profit of 2 Taler, if they are positioned on the target position of 50 . The 19 out of the 20 sliders which lead to a gain of 2 Taler are determined by chance. It is your task to position exactly one slider of all 20 sliders on the target position of 50. If you hit one of the 19 sliders, which lead to a profit of 2 Taler, these will be added to your account. In the case you do not hit any of the 19 sliders, you will not be given any Taler, in addition to not being allowed to take part in any lottery in any following period.

- If you win 2 Taler in the lottery A or the lottery B, you once again have the chance to choose between one of the lotteries A or B in the next period. The sliders which lead to the gaining of 2 Taler in either lottery A or B are again determined by chance in the next period. The 2 Taler are then again credited to your account.

- If you win 0 Taler in one period, you are automatically forwarded to a user interface for all the following periods. Here, you will be asked to make some estimations for which you will not receive any money. In addition, you are not allowed to take part in any lottery of the following periods.

\section{DEPOSIT: \{}

In all remaining periods, the participation fee of 0.5 Taler is neither deducted from, nor repaid to your account. The credit you have earned will remain unchanged for all the following periods. $\}$

\section{COPAYMENT: \{}

The credit you have earned will remain unchanged for all the following periods. BONUS: \{ 
Therefore, the bonus will not be credited to your account in any following period. The credit you have earned will remain unchanged for all the following periods.

- After every period you will be informed about your current amount of credit.

\section{Payments:}

- At the end of the experiment, your credit will be exchanged at an exchange rate of 1.50 Euro per 1 Taler. A show-up fee of 2.50 Euro is added to this amount which is then directly paid out to you in cash.

\section{Please note:}

- During the entire experiment, any form of communication is not permitted.

- All mobile phones must be switched off during the complete duration of the experiment.

- The decisions you make within this experiment are anonymous, i.e. none of the other participants gets to know the identity of a person who has made a specific decision.

- The payments are also handled anonymously. No other participant finds out how much money other participants are paid.

- Please remain seated until the end of the experiment. You will be called forward for your payment through your seat number.

Good luck and thank you for your participation in this experiment! 